\title{
A literature review of methods for providing enhanced operational oversight of teams in emergency management
}

\section{Chris Bearman* and Sophia Rainbird}

Appleton Institute, Central Queensland University,

44 Greenhill Road, Adelaide, SA, Australia

and

Bushfire and Natural Hazards CRC,

Melbourne, 3002, Australia

Email: c.bearman@cqu.edu.au

Email: s.rainbird@cqu.edu.au

${ }^{*}$ Corresponding author

\section{Benjamin P. Brooks}

National Centre for Ports and Shipping,

Australian Maritime College,

University of Tasmania,

Locked Bag 1397, Launceston, Tasmania, Australia

and

Bushfire and Natural Hazards CRC,

Melbourne, 3002, Australia

Email: benjamin.brooks@utas.edu.au

\section{Christine Owen}

Faculty of Education,

University of Tasmania,

Sandy Bay Campus,

Private Bag 66, Hobart, Tasmania, Australia

and

Bushfire and Natural Hazards CRC,

Melbourne, 3002, Australia

Email: Christine.Owen@utas.edu.au 


\title{
Steven Curnin
}

Tasmanian Institute of Law Enforcement Studies,

University of Tasmania,

Sandy Bay Campus,

Private Bag 22, Hobart, Tasmania, Australia

and

Bushfire and Natural Hazards CRC,

Melbourne, 3002, Australia

Email: steven.curnin@utas.edu.au

\begin{abstract}
Teamwork is an important component of effective emergency management. From time to time teamwork will break down in the complex situations involved in managing emergencies. It is important for people who have operational oversight of these teams to be able to detect breakdowns quickly and effectively. However, there is typically little guidance within many agencies about how best to do this. This paper reviews the literature on team monitoring by observers in emergency management and related domains and identifies four key approaches to monitoring teams: 1) coordination, cooperation and task-related communication; 2) information flow; 3) linguistic analysis; 4) team outputs. These methods provide a number of different options that agencies involved in emergency management can use as the basis for developing enhanced operational oversight of teams.
\end{abstract}

Keywords: emergency management; teamwork; monitoring; wildfire; response; safety.

Reference to this paper should be made as follows: Bearman, C., Rainbird, S., Brooks, B.P., Owen, C. and Curnin, S. (2018) 'A literature review of methods for providing enhanced operational oversight of teams in emergency management', Int. J. Emergency Management, Vol. 14, No. 3, pp.254-274.

Biographical notes: Chris Bearman is a Research Fellow at the Appleton Institute of Central Queensland University. His research interests are in applied cognitive psychology and human factors. This research involves conducting industry focused studies in laboratory and field settings with the aim of creating results that have both a strong theoretical underpinning and a robust application to industry. This involves working closely with industry partners and government organisations around the world. $\mathrm{He}$ is currently leading the Australian Bushfire and Natural Hazards CRC project on decision making, team monitoring and organisational learning.

Sophia Rainbird is an anthropologist and Senior Postdoctoral Research Fellow at Central Queensland University's Appleton Institute in South Australia. She specialises in safety, risk movement and resilience research. She applies qualitative research techniques to examine these themes within the fields of natural disasters, locomotive transportation, forced migration, chronic pain, young workers health and safety and ethnic community settlement. The majority of her work is in collaborative partnership with industry stakeholders (State and Federal Government, CRCs, NGOs) and interdisciplinary research teams producing research that is relevant, beneficial and with practical and applied outcomes. 
Benjamin P. Brooks is a human factors researcher and Associate Professor in the National Centre for Ports and Shipping at the Australian Maritime College. $\mathrm{He}$ has been a researcher and safety management system consultant for 15 years, and currently works on research in areas such as advanced training and safety systems, safety information systems and builds tools for the evaluation of safety management systems to support individual and team cognition. He works with a range of non-maritime and maritime industry stakeholders including regulators, private companies, pilotage organisations and port authorities.

Christine Owen is a Researcher with a focus on organisational behaviour and learning. She has extensive experience in researching and consulting in a number of high reliability domains, including the aviation field, in emergency medicine and more recently in the fire and emergency services industry. She has been involved in the Australian Bushfire Co-operative Research Centre since 2006 and is currently engaged in research with the Australian Bushfire and Natural Hazards Cooperative Research Centre.

Steven Curnin is a Research Fellow at the University of Tasmania. He works in a team at the Bushfire and Natural Hazards Cooperative Research Centre on a project investigating strategic decision making during emergency events. $\mathrm{He}$ also works in industry as an emergency management advisor, drawing on over 16 years of operational and policy experience in worldwide emergency management arrangements and working for or with state and national government agencies, not-for-profit organisations, multinational corporations and the military.

This paper is a revised and expanded version of a paper entitled 'Tools for monitoring teams in emergency management: EMBAM \& TBM' presented at AFAC 2016, Brisbane, Australia, 30 August-1 September, 2016.

\section{Introduction}

A large scale emergency response consists of a hierarchy of multiple teams working together. Each team in the hierarchy consists of team members and a team leader who coordinates that team's operation (Weick, 1993). In addition, the team will typically report up the organisational structure to a person who has operational oversight of that team's performance. The monitoring of teams by more senior officers, provides an important safety and quality assurance function for agencies that operate in inherently risky environments (AFAC, 2013; South Australian Country Fire Service, 2011; Grunwald and Bearman, 2017). While such monitoring may be conducted informally by senior officers in at least some stages of an emergency (Grunwald and Bearman, 2017) there is typically little guidance within many agencies on how to monitor teams effectively. This restricts the ability of senior officers to optimise their team's capabilities, enhance functionality, or conversely, foresee potential disruptions to their team's operational response.

As a team carries out its task and interacts with the environment, there will be disruptions to that team's performance from external circumstances (e.g., the scale, dynamism, and complexity of an emergency) and internal dynamics (e.g., changes to the coordination or composition of the team). To some extent disruptions in teamwork may 
be inevitable in something as complex and dynamic as emergency management, particularly in the early phases of an emergency (Bearman et al., 2015; Grunwald and Bearman, 2017). If these disruptions are not managed effectively then this can lead to teamwork breakdowns and an impaired operational response.

A team breakdown can broadly be defined as "a situation, or state, where there is a failure in coordination, cooperation or communication due to a difference in shared meaning that leads to a temporary loss in the ability to function effectively" (Bearman et al., 2015, p.18). Further, Bearman et al. (2010, 2015) have been able to identify a number of sub-components of breakdowns (known as disconnects) that may occur as a breakdown situation unfolds. These disconnects can be classified as informational, evaluative and operational. Informational disconnects are differences in the information possessed by team members; evaluative disconnects are differences in understanding of the same information; and operational breakdowns are differences in plans or expected actions (Bearman et al., 2010, 2015).

There are many examples in the emergency management literature where breakdowns in team functioning have led to significantly impaired operational responses (Owen et al., 2013; Comfort, 2007; Dickinson and McIntyre, 1997; Bearman et al., 2015). One example of a breakdown in team functioning is presented by Bearman et al. (2015) from their analysis of the Canberra Firestorm in Australia. In this breakdown team members did not have a common understanding of information presented at a meeting and developed different plans about where to place a control line.

Given that breakdowns are likely to occur throughout an emergency response, what is important is the identification and resolution of breakdowns before they can lead to an impaired operational response (Bearman et al., 2015). This places the emphasis on team monitoring as a method for ensuring effective emergency management. Team monitoring is therefore an important part of providing an emergency response that is safe and efficient. Providing senior officers with a clear and defined method of external team monitoring allows them to make better, more informed decisions that will enhance their teams' capabilities. The purpose of this paper then is to address the question "How can we monitor a team 's performance during an emergency?" We try to answer this question by considering how team monitoring is conducted in the published literature on teamwork in emergency management and other high reliability industries.

The literature on team monitoring encompasses many different domains and knowledge bases, such as: management, human resources, military, health, education, and psychology. Each has a slightly different foci, interpretation and application to team monitoring. For the purposes of this review we have reduced some of this complexity by focusing on domains that are directly relevant to emergency management and are potentially applicable to team monitoring from the perspective of providing operational oversight.

\section{Method}

The method used in this paper can be classified as a 'qualitative evidence synthesis' and may be considered a more specific form of article review (Grant and Booth, 2009). However, in the interests of convenience we use the familiar generic overarching category 'literature review' in this paper. 
To answer the question "How can we monitor a team's performance during an emergency?" literature was retrieved using a range of online tools (e.g., Scopus and Google Scholar) that provide access to peer reviewed journal articles via databases including EBSCO, PubMed, SAGE and ScienceDirect. A five phased literature review process was performed:

- initial net using broad search criteria

- application of specific criteria to identify papers within a 10 year period in high reliability domains (emergency management, healthcare, military, aviation, nuclear power)

- backward citation analysis of these articles - to identify historical methodology literature

- application of further criteria to identify papers replicable in the emergency management domain and excluding studies on individual team members

- qualitative inductive thematic analysis of identified research and methodology articles.

The initial literature search criteria included the keywords 'team monitoring' and 'teams', over the ten year time period between 2005 and 2015. Peer-reviewed articles that included as content the topic of team performance, monitoring and assessment were selected. Following the application of these broad criteria, a second phase applied more specific criteria to ensure that the literature was relevant to the question posed (i.e., monitoring emergency management teams). To be included in the literature review journal articles required the subject to be specifically about emergency services, or other high reliability industries (such as aviation, healthcare, the military and nuclear power). Further, the inclusion criteria required journal articles to report on research that utilised, or could potentially utilise, an external observer to assess the components of teamwork. The search based on these criteria yielded 195 research articles.

A third phase to the literature search identified key articles that were instrumental in the development of the methodological concepts and categories of teamwork. This was achieved by using a backward citation analysis of the initial 195 papers. Due to the historical nature of these articles and the reference origins, the time period of 2005 and earlier was applied. This identified an additional 78 articles (e.g., Entin and Entin, 2001; Fowlkes et al., 1994), that could potentially contribute to and inform the development of teamwork categories, arising from the literature, that are applicable to an emergency services context.

The fourth phase applied further criteria to the combined 273 articles (195 research articles and 78 methodology articles). Journal articles were required to include sufficient information to allow replication of the method used to monitor teams. Articles were also excluded where the focus of team monitoring centred on internal monitoring of teammates actions (see Marks and Panzer, 2004). These criteria provided a focus on methods that can be used by individuals tasked with observing teams or with strategic oversight of teams.

Once the specific criterion outlined above was applied, the article search yielded 57 articles that prima facie appeared to be applicable to emergency management. Of these, 39 research articles reported teamwork studies in high reliability industries and 
18 articles reported key seminal papers providing the methodology and origins of the reported measures underpinning the papers on teamwork studies.

The final phase of the literature review applied a qualitative analysis of the literature to identify the key aspects of the reported application of the team monitoring method in each paper. This was achieved by a thematic technique, rather than using a pre-formed coding scheme. This form of literature analysis used processes similar to the 'data analysis spiral' (Creswell, 2013; Leedy and Ormrod, 2005) through its iterative collection, documentation, extraction, classification and synthesis processes (Bearman and Bremner, 2013). Descriptors or phrases from each article were recorded as codes/themes. Numerous codes were sorted according to relevance or aggregated again into 'higher order' categories until repeated patterns of meaning were found (Thompson, 2013). This inductive process therefore produced a bottom-up, data driven approach to classifying methods of team performance monitoring (Bearman and Bremner, 2013; Thompson, 2013).

Each method included in the review contained clear descriptions and approaches that could be replicated within the domain of emergency management. For our purposes, we focused on processes that form monitoring points of a team's functioning, rather than the data collection tool (e.g., behavioural markers, observer coding techniques, conversation analysis, questionnaires, etc. $)^{1}$ as a standalone technique.

\section{Results}

From our five phase literature review process we identified four categories of performance monitoring. These four categories are presented in Table 1 and discussed below.

Table 1 Literature review results of different approaches to monitoring teams

\begin{tabular}{lc}
\hline Category & Journal articles \\
\hline Coordination, cooperation and task-related communication (3C) & 44 \\
Information flow (IF) & 5 \\
Linguistic analysis (LA) & 5 \\
Team outputs (TO) & 3 \\
Total & 57 \\
\hline
\end{tabular}

\subsection{Coordination, cooperation and task-related communication (3C)}

This approach to team monitoring requires people to make behavioural observations of the effectiveness of the task-related communication, coordination and cooperation (3C) of teams. Task-related communication is concerned with the accurate transfer of information to another person (McIntyre and Salas, 1995). Coordination is the correct and timely actions and contributions by all team members (Kozlowski and Bell, 2003). Through appropriate coordinating mechanisms, team members are able to sequence, synchronise, integrate, and complete tasks without wasting valuable resources (Wilson et al., 2007). Cooperation is about the shared attitudes and beliefs of teams (Wilson et al., 2007). The measures reported in the literature that used a $3 \mathrm{C}$ approach 
were extensive, with 24 measures and 44 publications (see Table 2) stemming from the military and medical fields.

Table 2 Measures of team monitoring that used a 3C approach

\begin{tabular}{|c|c|c|c|}
\hline No. & Measures & $\begin{array}{l}\text { Domains of } \\
\text { study }\end{array}$ & Reference \\
\hline 1 & $\begin{array}{l}\text { Targeted acceptable responses to } \\
\text { generated events or tasks (TARGET) }\end{array}$ & Military & Fowlkes et al. (1994) \\
\hline 2 & $\begin{array}{l}\text { Situational awareness linked } \\
\text { instances adapted to novel tasks } \\
\text { (SALIANT) }\end{array}$ & Military & $\begin{array}{l}\text { Muniz et al. (1998) and Smith et al. } \\
\text { (2007) }\end{array}$ \\
\hline 3 & $\begin{array}{l}\text { Simulation module for assessment of } \\
\text { resident's targeted event responses } \\
\text { (SMARTER) }\end{array}$ & Medical & Rosen et al. (2008) \\
\hline 4 & $\begin{array}{l}\text { Scenario-based performance } \\
\text { observation tool for learning in team } \\
\text { environments (SPOTLITE) }\end{array}$ & Military & MacMillan et al. (2013) \\
\hline 5 & $\begin{array}{l}\text { Anaesthesia crisis resource } \\
\text { management (ACRM) }\end{array}$ & Medical & Howard et al. (1992) \\
\hline 6 & $\begin{array}{l}\text { Anaesthetists' non-technical skills } \\
\text { (ANTS) }\end{array}$ & Medical & Fletcher et al. (2003) \\
\hline 7 & $\begin{array}{l}\text { Behaviourally anchored rating scales } \\
\text { (BARS) }\end{array}$ & Medical & $\begin{array}{l}\text { Shapiro et al. (2008) and Carretta and } \\
\text { Walters (1991) }\end{array}$ \\
\hline 8 & $\begin{array}{l}\text { Behavioural markers for neonatal } \\
\text { resuscitation }\end{array}$ & Medical & Thomas et al. (2004) \\
\hline 9 & $\begin{array}{l}\text { Crisis avoidance resource } \\
\text { management for anaesthetists } \\
\text { (CARMA) }\end{array}$ & Medical & Flin and Maran (2004) \\
\hline 10 & $\begin{array}{l}\text { Communication and teamwork skills } \\
\text { (CATS) }\end{array}$ & Medical & Frankel et al. (2007) \\
\hline 11 & $\begin{array}{l}\text { Emergency. medicine crisis resource } \\
\text { management behavioural } \\
\text { performance evaluation (EMCRM) }\end{array}$ & Medical & $\begin{array}{l}\text { Reznek et al. (2003) and Wallin et al. } \\
(2007)\end{array}$ \\
\hline 12 & $\begin{array}{l}\text { Mayo high performance teamwork } \\
\text { scale (MHPTS) }\end{array}$ & Medical & Malec et al. (2007) \\
\hline 13 & $\begin{array}{l}\text { Multi-disciplinary team (MDT) } \\
\text { performance assessment tool }\end{array}$ & Medical & Lamb et al. (2011) \\
\hline 14 & $\begin{array}{l}\text { Surgeons' non-technical skills in the } \\
\text { operating theatre (NOTSS) }\end{array}$ & Medical & Yule et al. $(2006,2008)$ \\
\hline 15 & Non-technical skills (NOTECHS) & Medical & Mishra (2014) \\
\hline 16 & $\begin{array}{l}\text { Observational skill-based clinical } \\
\text { assessment tool for resuscitation } \\
\text { (OSCAR) }\end{array}$ & Medical & Walker et al. (2011) \\
\hline 17 & $\begin{array}{l}\text { Objective structured assessment of } \\
\text { technical skill (OSATS) }\end{array}$ & Medical & $\begin{array}{l}\text { Martin et al. (1997) and Marriott } \\
\text { et al. (2009) }\end{array}$ \\
\hline 18 & $\begin{array}{l}\text { Observational teamwork assessment } \\
\text { for surgery (OTAS) }\end{array}$ & Medical & $\begin{array}{l}\text { Healey et al. (2004) and Undre et al. } \\
(2007)\end{array}$ \\
\hline
\end{tabular}


Table 2 Measures of team monitoring that used a 3C approach (continued)

\begin{tabular}{|c|c|c|c|}
\hline No. & Measures & $\begin{array}{l}\text { Domains of } \\
\text { study }\end{array}$ & Reference \\
\hline 19 & $\begin{array}{l}\text { Ottawa crisis resource management } \\
\text { global rating scale (Ottawa GRS) }\end{array}$ & Medical & Kim et al. (2006) \\
\hline 20 & $\begin{array}{l}\text { Procedure-based assessment (PBAs) } \\
\text { tool }\end{array}$ & Medical & Pitts and Rowley (2009) \\
\hline 21 & Revised teamwork behaviour matrix & Medical & Small et al. (1999) \\
\hline 22 & Simulation team assessment tool & Medical & Reid et al. (2012) \\
\hline 23 & Team dimensions rating form & Medical & Morey et al. (2002) \\
\hline 24 & Teamwork behavioural rating scales & $\begin{array}{l}\text { Medical and } \\
\text { health; military }\end{array}$ & $\begin{array}{l}\text { Johnston et al. (1997), Dwyer et al. } \\
\text { (1999), Entin and Entin (2001), } \\
\text { Schaafstal et al. (2001), Foltz et al. } \\
\text { (2003), Shanahan et al. (2007), } \\
\text { Wallin et al. (2007), Zaccaro et al. } \\
\text { (2009), Burtscher et al. (2010), } \\
\text { Kolbe et al. (2010, 2013), } \\
\text { Hollenbeck et al. (2012), Mitchell } \\
\text { and Flin (2012), Arora et al. (2013) } \\
\text { and Tims et al. (2013) }\end{array}$ \\
\hline
\end{tabular}

\subsubsection{Approach}

This approach provides a very detailed method of identifying markers, or points of $3 \mathrm{C}$ that are representative of effective team performance. During or at the end of an exercise observers rate the team's performance across a number of dimensions that indicate 3Cs. Typically each dimension includes a scale providing a corresponding example of poor team behaviour at one end of the scale, an example of good team behaviour at the other end. This provides the observer with an opportunity to rate the observed team behaviour accordingly (Entin and Entin, 2001). All 24 tools focused on 3C identified in the literature were based on the behavioural marker approach to identify indicators of the presence or absence of requisite team $3 \mathrm{C}$ cognitive and behavioural processes.

\subsubsection{Application and benefits}

The studies that have used a $3 \mathrm{C}$ approach allowed observers to assess team performance in terms of the specific behaviours that may indicate an issue or identify where enhanced behaviours may improve team performance. For example, the scenario-based performance observation tool for learning in team environments (SPOTLITE) uses behavioural markers to allow observers to measure team performance. MacMillan et al. (2013) reported on the problem of identifying team readiness for active F-16 combat fighter pilots because of the complexity of the environment. In this study, each team consisted of four pilots each with an observable cockpit display that required the absolute attentive focus of the observers (MacMillan et al., 2013). Observers used an electronic, rather than paper based method of rating team performance, because of its flexibility in accessing the behaviour marker fields corresponding to the unfolding real time scenario. Observers responded to task specific questions on a 1-5 scale. For example, targeting and engagement behaviours that related to 'radar' tasks were rated using the corresponding practical question: 'how appropriately is the radar set up?' This method provided a 
useful tool to ascertain the team performance status by identifying the specific behaviours of fighter pilots in a complex environment. The $3 \mathrm{C}$ tool provided information to external observers which could then be used to specifically tailor pilot education. The information garnered by $3 \mathrm{C}$ also assisted the external observers to identify pilot readiness for real combat missions.

Studies differed in the format required to document observations, with some studies employing a behavioural marker 'checklist' rather than a behavioural marker 'scale'. Wilson et al. (2007) isolated specific behaviours linked to a set of detailed indicators of team performance that may point to problems in team coordination, communication and cooperation. For example, cooperation is defined by behaviours around team orientation, collective efficacy, mutual trust and team cohesion. Each behaviour marker has assigned three to four questions posed to the observer who provides a 'yes' or 'no' response. Team orientation, for instance, can be checked via the questions "Did team members put group goals ahead of individual goals?", "Were team members collectively motivated, and did they show an ability to coordinate?", "Did team members evaluate each other and use inputs from other team members?" and "Did team members exhibit 'give-and-take' behaviours?" These behavioural markers formed part of a taxonomy of factors that lead to fratricide incidents in the battlefield. This study indicates the potential applicability of behavioural markers to assist observers in the identification of team performance issues.

\subsubsection{Limitations}

While the $3 \mathrm{C}$ approach has shown to be a useful method of monitoring teams it does have a number of limitations. $3 \mathrm{Cs}$ is multifaceted and can therefore be complex to conceptualise and operationalise (Rousseau, 1985). It may also be difficult to observe some aspects of 3C, such as whether people are correcting errors made by others or whether team members exhibit trust in each other. Some applications of 3Cs may be limited by being developed in a specific context (e.g., Yule et al., 2008; Mishra et al., 2012) that does not necessarily generalise to other contexts. The detailed observations and coding required in methods of $3 \mathrm{C}$ may also be time consuming and hard to carry out in some high tempo operations.

\subsection{Information flow (IF)}

Information flow (IF) is an approach to monitoring teams that focuses on the patterns of interaction between the team members. This approach can be characterised as who talks to whom and when. There were five papers from the military, medical, space and nuclear energy fields that reported on observational studies of team IF (see Table 3 for more details).

Table 3 Measures of team monitoring that used an IF approach

\begin{tabular}{llll}
\hline No. & Measures & Domains of study & Reference \\
\hline 1 & Observation coding systems & Medical & Burtscher et al. (2011) \\
2 & Observation coding systems & Medical & Burtscher et al. (2010) \\
3 & Observation coding systems & Nuclear & Patrick et al. (2006) \\
4 & Observation coding systems & Military & Entin and Entin (2001) \\
5 & Observation coding systems & Space & Fischer et al. (2007) \\
\hline
\end{tabular}




\subsubsection{Approach}

All five papers reported examining team IF using observation coding systems. These coding systems were individually tailored to simulation studies and required the identification of particular categories associated with the flow of information. While the categories were different in each study, categories of IF are generally based on who initiated contact with another team member, who the contact was with, whether the request pushed or pulled information, when the interaction occurred and how long the process took.

\subsubsection{Application and benefits}

Studies that have used an IF approach to examining team performance have found that this approach allows observers to identify and plan targeted improvements to team practices (Aubé et al., 2014; Rousseau et al., 2006; Marks et al., 2001; Entin and Entin, 2001). For instance, Burtscher et al. (2010) video-recorded 22 anaesthesia teams which were then coded by an observer using an observation coding system to study information flow. Observers assigned a code according to the observation system (e.g., information request), its duration (e.g., $3.5 \mathrm{~s}$ ), and the acting person (e.g., nurse anaesthetist). They found when faced with challenging procedures, anaesthesia teams adapted their management of the task in response. They concluded that this approach could assist in targeting appropriate training.

Another example of a study of information flow on team performance was conducted by Patrick et al. (2006). Patrick et al. (2006) developed an observation system tool to identify the interaction and information flow between workers during a simulated nuclear plant emergency. The communications that occurred could be categorised according to detection, diagnosis, and control tasks (Patrick et al., 2006). Each category was then assigned a number of codes that described the associated form of information exchange, the type of interaction and management of key tasks. Observers used this coding system to capture the quantity, directionality, timing, and type of communications that occurred within and between teams (Patrick et al., 2006). This allowed deficiencies in supervisory monitoring to be identified.

\subsubsection{Limitations}

While team IF can provide useful information in identifying team performance issues, this approach does possess a number of potential problems. Examining IF can potentially detect a problem, but does not necessarily determine why the problem is occurring or how it can be fixed. Many of the methods are specific to the context in which they were developed and some require a base measure of effective team functioning from which to run a data comparison. In a dynamic environment (such as emergency management) base measures may be difficult to derive and may not be valid at different times in an operation. Like the $3 \mathrm{C}$ approach the detailed observations and coding required may be time consuming and hard to carry out in some high tempo operations.

\subsection{Linguistic analysis (LA)}

Another approach to examining team performance is to consider the linguistic element of task performance and its effect on team functionality and outcomes. Linguistic elements 
are the non-content related aspects of language (e.g., the number and type of words, negations, assents and positive/negative emotion). There were five papers from the emergency services, aviation, military and space domains that used linguistic analysis (see Table 4 for more details).

Table 4 Measures of team monitoring that used an LA approach

\begin{tabular}{llll}
\hline No. & Measures & Domains of study & Reference \\
\hline 1 & Word frequencies & Emergency services & Khawaja et al. (2012) \\
2 & Word frequencies & Aviation & Sexton and Helmreich (2000) \\
3 & Word frequencies & Aviation & Sexton and Helmreich (2003) \\
4 & Latent semantic analysis (LSA) & Military & Foltz et al. (2003) \\
5 & Word frequencies & Space & Fischer et al. (2007) \\
\hline
\end{tabular}

\subsubsection{Approach}

The studies in this category are based on linguistic analysis that developed from research into communication in aviation. There are certain aspects of communication that are not based on the content of the communication but may nevertheless be important in understanding team performance. These categories are things like: number of words used; sentence punctuation; percentage of words over six letters; 1st person plural (we, ours, us); negations (no, never, not); assents (yes, ok, mmhmm); positive emotions (happy, pretty good); anger (hate, resentment) and cognitive processes (cause, know, effect, maybe). This approach assumes that these observable non-content aspects of communications correlate with how the team is performing and can therefore be used to measure the effectiveness of the team (Sexton and Helmreich, 2000).

\subsubsection{Application and benefits}

Khawaja et al. (2012) used LA to study the interactions of bushfire emergency management teams during a computerised bushfire management exercise. They used linguistic inquiry and word count (LIWC), an automatic text analysis and extraction software tool, to identify linguistic changes that might indicate behavioural responses to high and low cognitive loads. Specifically, the researchers analysed "sentence length, use of agreement and disagreement phrases, and use of personal pronouns, including both singular and plural pronoun types" of bushfire emergency management team communications. The study involved video and audio recording of the emergency services teams which were later transcribed and rated against four cognitive load levels: low load (casual), medium load (routine), high load (challenging) and very high load (very challenging). They identified that teams experiencing high-cognitive load tasks found it harder to reach agreements.

Fischer et al. (2007) used linguistic analysis to analyse team work in a search and rescue task. These dimensions were based on expressed effect and its positive or negative valence; and interactive patterns including acknowledgements, disagreements, elaborations, answers (to Questions), and missing responses of communication. Fischer et al. identified more positive emotion words (e.g., humour, empathy and praise), more assenting responses following another team member's 
contribution (e.g., acknowledgements, elaborations and continuations) and more use of humour, praise and empathy amongst high performing teams. In contrast, low performing teams used fewer positive emotion words, more frequently missed responses following another team member's contribution, and used more insults and defensive utterances.

\subsubsection{Limitations}

Linguistic markers have been shown to correlate with team performance. However, it is often not clear whether high performing teams show more of these elements of communication because they are successful, or they are successful because they show these types of communication (Fischer et al., 2007). The types of communication patterns that were observed are also likely to be context dependent, according to the particular type of group interaction that was observed. Like the $3 \mathrm{C}$ and IF approaches the detailed observations and coding required may be time consuming and hard to carry out in some high tempo operations.

\subsection{Team outputs (TO)}

Another way to evaluate the performance of a team is to examine the quality and timeliness of the outputs that the team produces. If the outputs that a team is producing are missing, incomplete or of poor quality this indicates that there is likely to be a problem with that team. There were three studies that reported on team outputs (TO) as an observable method of monitoring team performance in the domains of military and emergency services (see Table 5 for more details).

Table 5 Measures of team monitoring that used a TO approach

\begin{tabular}{llll}
\hline No. & Measures & Domains of study & Reference \\
\hline 1 & Behaviourally anchored rating scale & Military & Carretta and Walters (1991) \\
2 & $\begin{array}{l}\text { Emergency management aide } \\
\text { memoire }\end{array}$ & Emergency services & Grunwald and Bearman (2017) \\
3 & $\begin{array}{l}\text { On-scene command team (OSCT) } \\
\text { performance effectiveness scale }\end{array}$ & Emergency services & Van Der Haar et al. (2013) \\
\hline
\end{tabular}

\subsubsection{Approach}

The studies in this category applied different methods to develop tools that focused on the quality and timeliness of the team's outputs. TO may refer to the outputs of the broader overall mission, to specific tasks, or subsets of these tasks. In the context of emergency management operations for example, a team output may be the production of timely and well-constructed incident action plans (IAPs). This approach has generally been applied to simulated exercises and can be utilised by an observer who considers the output of the team at various intervals.

\subsubsection{Application and benefits}

Grunwald and Bearman (2017) conducted a table top simulation with a concurrent semistructured interview of a multi-emergency event (major bushfire, multi-car accident, and 
infrastructure fire). The scenario used pre-prepared teamwork breakdowns so that the way that participants identified and resolved these breakdowns in teamwork could be established. The study found that one of the ways that participants identified breakdowns was based on the output of that team. If information coming from the team conflicted with their expectations of how the event should be unfolding or was missing, incomplete, or duplicated this indicated that there was a problem in the team that needed to be investigated. In addition a number of methods of resolving breakdowns in teams could be identified (delegation, providing additional resources, mentoring, using authority and replacing team members). Based on the identification and resolution strategies identified in the study Grunwald and Bearman (2017) proposed an aide memoire to help senior emergency managers better identify breakdowns in their teams. This aide memoire was designed so it could easily be integrated into the normal ongoing flow of activities carried out by emergency managers.

Van der Haar et al. (2013) developed a method for monitoring team effectiveness initially out of a short open-ended question survey completed by emergency management team members. Although the focus of this study was on team members' self-evaluation, this study developed a 21-item OSCT (on-scene command team) performance effectiveness scale that could equally be used by an external observer. The components of the scale included: image of the situation, decisions, information management, cooperation with the tactical team, quality of actions, workplace safety, goal achievement and error rate. This scale was designed to capture context-specific information which would allow the evaluation of command and control teams and to initiate dialogue around improving team effectiveness.

\subsubsection{Limitations}

While monitoring team outputs appears to be reasonably easy to apply in emergency management this approach does have a number of limitations. Perhaps the most problematic is that focusing on team outputs will detect team performance problems only at a fairly general level as the contributing factors to those outputs are not taken into consideration (Shanahan et al., 2007; Salas et al., 2007). These approaches will also not necessarily detect all teams that are operating ineffectively. Teams could quite conceivably have impaired functioning that has not yet shown up in the quality and timeliness of their outputs.

\section{Discussion}

This paper presents a detailed examination of the literature on how to monitor teams from the position of operational oversight. The literature review identified four main approaches to team monitoring:

- coordination, cooperation and task-related communication (3C)

- information flow (IF)

- linguistic analysis (LA)

- team outputs (TO). 
Each of these approaches contains methods that have demonstrated that they are a viable way of monitoring teams from the perspective of an observer who is not part of the team. The literature shows that there are many potential methods of providing operational oversight of teams in emergency management. Although each type of team monitoring tool has a slightly different methodology, they all have the same general aim which is to provide a method of observing and documenting the points of team interaction and then to compare these documented points against a baseline of appropriate and functional interactions (which may or may not be formally articulated).

The team monitoring tools are concerned with identifying that a problem exists and clarifying what that problem is. We see this as being one of the most important parts of the process. Solutions typically flow on from the identification of problems in teamwork and may be fairly straightforward (such as making sure everyone is included in communication) or more complex (such as providing retraining to a disruptive individual). However, the tools do not necessarily provide solutions rather they offer data leading to the identification of the problem from which solutions can then be developed in conjunction with the team.

Each of the broad approaches to team monitoring possess limitations. Limitations of each approach were considered in the relevant sections but more general limitations can also be identified that apply to all of the approaches using observers to evaluate team performance. These more general limitations concern the difficulty of observing teams in real time, having sufficient data to make a judgement of the team's performance and having enough time available to complete the observation. Many of the methods used to monitor teams require careful observation and detailed coding of observations, which takes time and requires access to team-specific information. In a fast-paced context observers are likely to experience considerable difficulty in paying close attention to all team members' actions while simultaneously recording their observations (MacMillan et al., 2013). These limitations may also be particularly problematic for people who are not co-located with a team and who therefore do not have the ability to directly observe how that team is functioning.

MacMillan et al. (2013) suggest two ways of addressing the issues associated with the ability of observers to code aspects of teamwork in real-time. They suggested that: coding should be reviewed at a later stage during the team debriefing, or that observers should complete an additional instrument after the scenario and compare to the results gained during the real-time coding. However, these solutions raise questions about the accuracy of the rating and would potentially increase workload and the time required to use the tool. In response to the accurate measure of team performance one solution might be to increase the number of observers. Yet, Mjelde (2013) found that too many observers becomes intrusive. They suggest that there should be no more than two observers per team at one time. This suggests that greater consideration must be given to the appropriate number of observers as well as the role of covert and overt forms of observation.

It may also be difficult for people who have an operational role to find enough time to complete a detailed extended examination of a team. Emergency management operations are frequently high tempo and people may simply not have enough time to complete the process. In such cases, it may be that team monitoring should be conducted by a person who has an opportunity to observe the team but does not have a specific operational role in the emergency (e.g., an external observer, assistant or Chaplin). Alternatively, team monitoring could be carried out as part of a Safety Officer's role. It may also be possible 
to use some of the tools (e.g., Wilson et al.'s breakdown behavioural markers) during periods of relative calm to reflect on how the team is performing.

The specific and general limitations of the methods of monitoring teams suggest that it is unlikely that a method of monitoring teams can be simply applied to emergency management. Instead these methods need to be carefully translated into each emergency management context in which they will be used. Many of the studies examined in this literature review were based on exercises rather than real life events. While exercises are often realistic versions of operational situation, it is hard to recreate the pressure and emotion of a real life event. Therefore, the translation of methods into the context in which they will be used should include extensive trails in real operational situations. It also seems worthwhile to use multiple approaches to examine team performance to offset the specific limitations of each approach. For example, a method of monitoring information flow can be used together with examination of linguistic markers. Alternatively, a method of monitoring team outputs could be used to initially detect that there is a problem, which can then be investigated with a more detailed approach, like communication, coordination, and cooperation processes.

Figure 1 Model of monitoring points of team performance (see online version for colours)

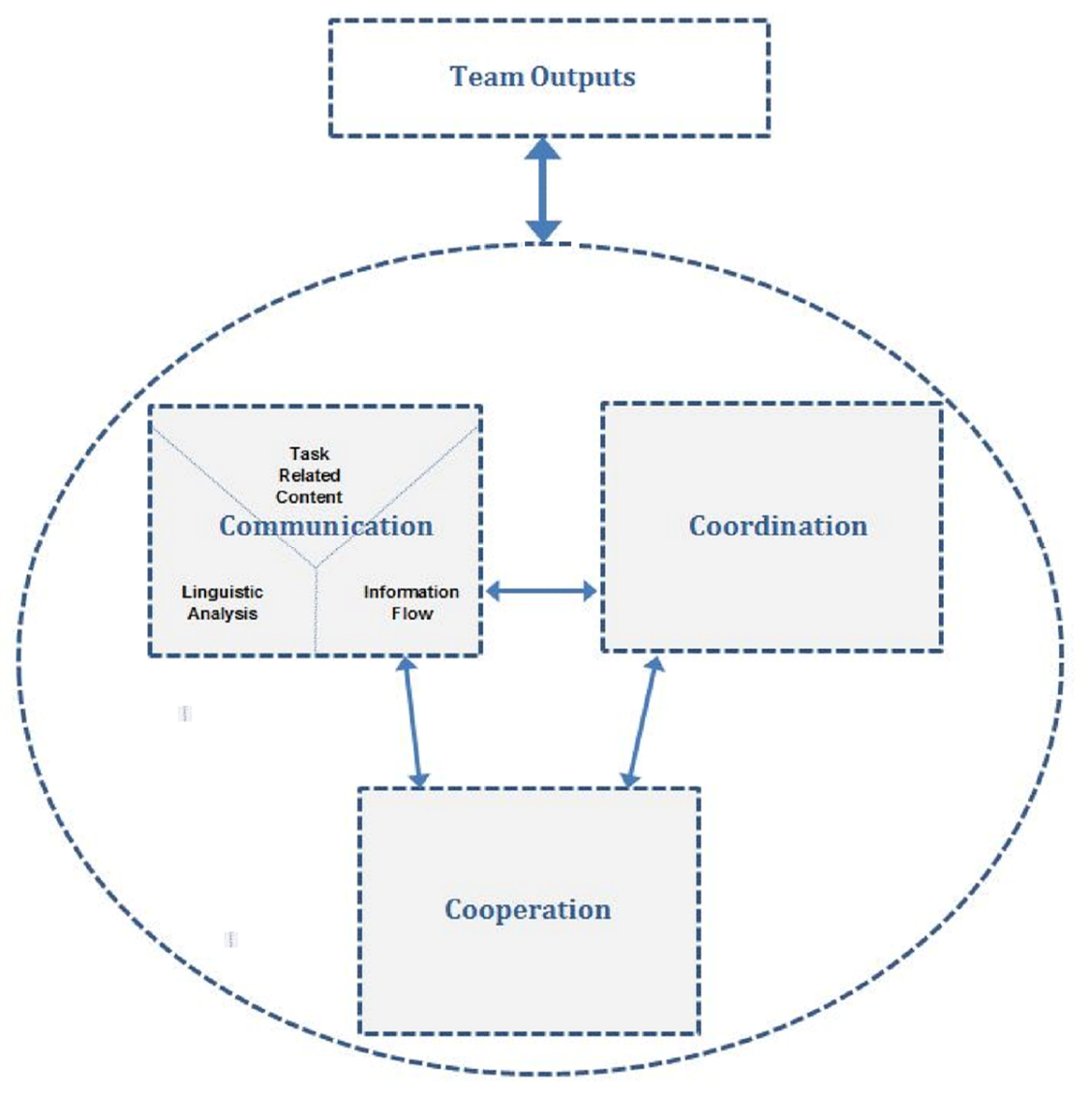


Our focus so far has been on individual methods. We also considered the interrelatedness of components, by taking an inter (across methods), rather than intra (within methods) approach to the qualitative evidence synthesis. There appears to be a close relationship between the communication components of 3C (which is concerned with effective communication of information) and information flow (which is concerned with who talks to whom and when) and linguistic elements (which is concerned with the non-task related components of communication). Since each of these aspects of communication provide different points for monitoring teams they are considered separately in this paper. However, we are not proposing that these concepts are necessarily theoretically distinct, only that they provide different ways to look at a team's functioning. Coordination is concerned with correct and timely actions and contributions by all team members (Kozlowski and Bell, 2003). This ensures that the team carries out activities in an appropriate manner. Underpinning both communication and coordination are the shared attitudes and beliefs of the team (i.e., the team's cooperation) (Wilson et al., 2007). A tentative model of the interaction of these various components is presented in Figure 1. It is likely that the different aspects of communication, coordination and cooperation all mutually influence each other and that together these processes create the team output. The model is designed to show the different monitoring points that can be used to examine team performance rather than being a definitive model of teamwork. As such the use of boxes and circles in the figure serve an illustrative rather than a theoretical purpose.

In conclusion, the literature review presented in this paper has identified a number of different approaches to monitoring teams that can potentially be adapted for use in emergency management. Together these approaches may be considered to provide the key monitoring points of teams. While each method has shown benefits in the specific applications in which it has been used a number of limitations of each approach could be identified. This suggests that rather than being simply applied to emergency management the methods of monitoring teams need to be tailored to the specific context in which they will be used. It also seems reasonable to use a number of different methods in conjunction. The next step is to test these methods in simulations/exercises and real operations. Monitoring teams from the position of operational oversight is an important way of ensuring that the response to an emergency is safe and effective. The different methods identified in this paper provide potential options for agencies involved in emergency management to carry out this function more effectively.

\section{References}

AFAC (2013) The Australasian Inter-Service Incident Management System (AIIMS), Australasian Fire and Emergency Service Authorities Council (AFAC), Melbourne.

Arora, V.M., Greenstein, E.A., Woodruff, J.N., Staisiunas, P.G. and Farnan, J.M. (2013) 'Implementing peer evaluation of handoffs: associations with experience and workload', Journal of Hospital Medicine, Vol. 8, No. 3, pp.132-136.

Aubé, C., Brunelle, E. and Rousseau, V. (2014) 'Flow experience and team performance: the role of team goal commitment and information exchange', Motivation and Emotion, Vol. 38, No. 1, pp.120-130.

Bearman, C. and Bremner, P.A. (2013) 'A day in the life of a volunteer incident commander: errors, pressures and mitigating strategies', Applied Ergonomics, Vol. 44, No. 3, pp.488-495. 
Bearman, C., Grunwald, J.A., Brooks, B.P. and Owen, C. (2015) 'Breakdowns in coordinated decision making at and above the incident management team level: an analysis of three large scale Australian wildfires', Applied Ergonomics, Vol. 47, No. 1, pp.16-25.

Bearman, C., Paletz, S.B.F., Orasanu, J. and Thomas, M.J.W. (2010) 'The breakdown of coordinated decision making in distributed systems', Human Factors, Vol. 52, No. 2, pp.173-88.

Burtscher, M.J., Kolbe, M., Wacker, J. and Manser, T. (2011) 'Interactions of team mental models and monitoring behaviors predict team performance in simulated anesthesia inductions', Journal of Experimental Psychology: Applied, Vol. 17, No. 3, pp.257-269.

Burtscher, M.J., Wacker, J., Grote, G. and Manser, T. (2010) 'Managing nonroutine events in anesthesia: the role of adaptive coordination', Human Factors: The Journal of the Human Factors and Ergonomics Society, Vol. 52, No. 2, pp.282-294.

Carretta, T.R. and Walters, L.C. (1991) The Development of Behaviorally Anchored Rating Scales (BARS) for Evaluating USAF Pilot Training Performance, US Air Force Systems Command, Research Division Brooks Air Force Base, Texas, USA.

Comfort, L.K. (2007) 'Crisis management in hindsight: cognition, communication, coordination, and control', Public Administration Review, Vol. 67, No. 1, pp.189-197.

Creswell, J.W. (2013) Research Design: Qualitative, Quantitative, and Mixed Methods Approaches, Sage Publications, Los Angeles.

Dickinson, T.L. and McIntyre, R.M. (1997) 'A conceptual framework for teamwork measurement', Team Performance Assessment and Measurement, Psychology Press, New Jersey, USA, pp.19-43.

Dwyer, D.J., Oser, R.L., Salas, E. and Fowlkes, J.E. (1999) 'Performance measurement in distributed environments: Initial results and implications for training', Military Psychology, Vol. 11, No. 2, pp.189-215.

Entin, E.E. and Entin, E.B. (2001) 'Measures for evaluation of team processes and performance in experiments and exercises', Proceedings of the 6th International Command and Control Research and Technology Symposium, 19-21 June, 2001, Annapolis, MD, USA, pp.1-14.

Fischer, U., McDonnell, L. and Orasanu, J. (2007) 'Linguistic correlates of team performance: toward a tool for monitoring team functioning during space missions', Aviation, Space, and Environmental Medicine, Vol. 78, No. 1, pp.86-95.

Fletcher, G., Flin, R., McGeorge, P., Glavin, R., Maran, N. and Patey, R. (2003) 'Anaesthetists' non-technical skills (ANTS): evaluation of a behavioural marker system', British Journal of Anaesthesia, Vol. 90, No. 5, pp.580-588.

Flin, R. and Maran, N. (2004) 'Identifying and training non-technical skills for teams in acute medicine', Quality and Safety in Health Care, Vol. 13, No. 1, pp.80-84.

Foltz, P.W., Laham, D. and Derr, M. (2003) 'Automated speech recognition for modeling team performance', Proceedings of the Human Factors and Ergonomics Society Annual Meeting, SAGE Publications, pp.673-677.

Fowlkes, J.E., Lane, N.E., Salas, E., Franz, T. and Oser, R. (1994) 'Improving the measurement of team performance: the TARGETs methodology', Military Psychology, Vol. 6, No. 1, pp.47-61.

Frankel, A., Gardner, R., Maynard, L. and Kelly, A. (2007) 'Using the communication and teamwork skills (CATS) assessment to measure health care team performance', The Joint Commission Journal on Quality and Patient Safety, Vol. 33, No. 9, pp.549-558.

Grant, M.J. and Booth, A. (2009) 'A typology of reviews: an analysis of 14 review types and associated methodologies', Health Information \& Libraries Journal, Vol. 26, No. 2, pp.91-108.

Grunwald, J.A. and Bearman, C. (2017) 'Identifying and resolving coordinated decision making breakdowns in emergency management', International Journal of Emergency Management, Vol. 13, pp.68-86. 
Healey, A.N., Undre, S. and Vincent, C.A. (2004) 'Developing observational measures of performance in surgical teams', Quality and Safety in Health Care, Vol. 13, No. 1, pp.33-40.

Hollenbeck, J.R., Beersma, B. and Schouten, M.E. (2012) 'Beyond team types and taxonomies: a dimensional scaling conceptualization for team description', Academy of Management Review, Vol. 37, No. 1, pp.82-106.

Howard, S.K., Gaba, D.M., Fish, K.J., Yang, G. and Sarnquist, F.H. (1992) 'Anesthesia crisis resource management training: teaching anesthesiologists to handle critical incidents', Aviation, Space, and Environmental Medicine, Vol. 63, No. 9, pp.763-770.

Johnston, J., Smith-Jentsch, K. and Cannon-Bowers, J. (1997) 'Performance measurement tools for enhancing team decision making', in Brannick, M.T., Salas, E. and Prince, C. (Eds.): Team Performance Assessment and Measurement: Theory, Methods, and Applications, Erlbaum, Mahwah, NJ, pp.311-327.

Khawaja, M.A., Chen, F. and Marcus, N. (2012) 'Analysis of collaborative communication for linguistic cues of cognitive load', Human Factors: The Journal of the Human Factors and Ergonomics Society, Vol. 54, No. 4, pp.518-529.

Kim, J., Neilipovitz, D., Cardinal, P., Chiu, M. and Clinch, J. (2006) A pilot study using highfidelity simulation to formally evaluate performance in the resuscitation of critically ill patients: The University of Ottawa critical care medicine, high-fidelity simulation, and crisis resource management I study', Critical Care Medicine, Vol. 34, No. 8, pp.2167-2174.

Kolbe, M., Burtscher, M.J. and Manser, T. (2013) 'Co-ACT - a framework for observing coordination behaviour in acute care teams', BMJ Quality \& Safety, Vol. 22, No. 1, pp.596-605.

Kolbe, M., Künzle, B., Zala-Mezö, E., Burtscher, M.J., Wacker, J., Spahn, D.R. and Grote, G. (2010) 'The functions of team monitoring and 'talking to the room'for performance in anesthesia teams', Proceedings of the Human Factors and Ergonomics Society Annual Meeting, SAGE Publications, pp.857-861.

Kozlowski, S.W. and Bell, B.S. (2003) 'Work groups and teams in organizations', in Borman, W., Ilgen, D. and Klimoski, R. (Eds.): Handbook of Psychology: Industrial and Organizational Psychology, Wiley, London, pp.333-375.

Lamb, B., Sevdalis, N., Mostafid, H., Vincent, C. and Green, J. (2011) 'Quality improvement in multidisciplinary cancer teams: an investigation of teamwork and clinical decision-making and cross-validation of assessments', Annals of Surgical Oncology, Vol. 18, No. 13, pp.3535-3543.

Leedy, P.D. and Ormrod, J.E. (2005) Practical Research: Planning and Design, 8th ed., Prentice Hall, Upper Saddle River, NJ.

MacMillan, J., Entin, E.B., Morley, R. and Bennett Jr., W. (2013) 'Measuring team performance in complex and dynamic military environments: the SPOTLITE method', Military Psychology, Vol. 25, No. 3, pp.266-279.

Malec, J.F., Torsher, L.C., Dunn, W.F., Wiegmann, D.A., Arnold, J.J., Brown, D.A. and Phatak, V. (2007) 'The mayo high performance teamwork scale: reliability and validity for evaluating key crew resource management skills', Simulation in Healthcare, Vol. 2, No. 1, pp.4-10.

Marks, M.A. and Panzer, F.J. (2004) 'The influence of team monitoring on team processes and performance', Human Performance, Vol. 17, No. 1, pp.25-41.

Marks, M.A., Mathieu, J.E. and Zaccaro, S.J. (2001) 'A temporally based framework and taxonomy of team processes', Academy of Management Review, Vol. 26, No. 3, pp.356-376.

Marriott, J., Purdie, H., Crossley, J. and Beard, J. (2009) Implementing the Assessment of Surgical Skills and Nontechnical Behaviours in the Operating Room, Ashgate, Farnham.

Martin, J.A., Regehr, G., Reznick, R., MacRae, H., Murnaghan, J., Hutchison, C. and Brown, M. (1997) 'Objective structured assessment of technical skill (OSATS) for surgical residents', Br. J. Surg., Vol. 84, No. 2, pp.273-278. 
McIntyre, R.M. and Salas, E. (1995) 'Measuring and managing for team performance: emerging principles from complex environments', in Guzzo, R.A. and Salas, E. (Eds.): Team Effectiveness and Decision Making in Organizations, Jossey-Bass, San Francisco, pp.9-45.

Mishra, A. (2014) 'Trust and teamwork matter': community health workers' experiences in integrated service delivery in India', Global Public Health, Vol. 9, No. 8, pp.960-974.

Mishra, A., Catchpole, K., Hirst, G., Dale, T. and McCulloch, P. (2012) 'Rating operating theatre teams-surgical NOTECHS', in Flin, R. and Mitchell, L. (Eds.): Safer Surgery, Ashgate, London, pp.103-117.

Mitchell, M.L. and Flin, R. (2012) Safer Surgery: Analysing Behaviour in the Operating Theatre, Ashgate Publishing, Ltd.

Mjelde, F.V. (2013) Performance Assessment of Military Teams in Simulator and Live Exercises, Master's Thesis, Naval Postgraduate School and The Royal Norwegian Naval Academy, Monterey CA, http://oai.dtic.mil/oai/oai?verb=getRecord\&metadataPrefix=html\&identifier =ADA589791 (28 May, 2016).

Morey, J.C., Simon, R., Jay, G.D., Wears, R.L., Salisbury, M., Dukes, K.A. and Berns, S.D. (2002) 'Error reduction and performance improvement in the emergency department through formal teamwork training: evaluation results of the MedTeams project', Health Services Research, Vol. 37, No. 6, pp.1553-1581.

Muniz, E., Stout, R., Bowers, C. and Salas, E. (1998) 'A methodology for measuring team situational awareness: situational awareness linked indicators adapted to novel tasks (SALIENT)', Nato Human Factors and Medicine Panel On Collaborative Crew Performance in Complex Systems, North Atlantic Treaties Organisation, Neuilly-sur-Seine, Edinburgh, April, pp.20-24.

Owen, C., Bearman, C., Brooks, B., Chapman, J., Paton, D. and Hossain, L. (2013) 'Developing a research framework for complex multi-team coordination in emergency management', International Journal of Emergency Management, Vol. 9, No. 1, pp.1-17.

Patrick, J., James, N. and Ahmed, A. (2006) 'Human processes of control: tracing the goals and strategies of control room teams', Ergonomics, Vol. 49, Nos. 12-13, pp.1395-1414.

Pitts, D. and Rowley, D. (2009) 'Competence evaluation in orthopaedics - a 'bottom up' approach', Safer Surgery: Analysing BEHAVIOUR in the Operating Theatre, Ashgate Publishing Ltd., Farnham, England, No. 27-46.

Reid, J., Stone, K., Brown, J., Caglar, D., Kobayashi, A., Lewis-Newby, M., Partridge, R., Seidel, K. and Quan, L. (2012) 'The simulation team assessment tool (STAT): development, reliability and validation', Resuscitation, Vol. 83, No. 7, pp.879-886.

Reznek, M., Smith-Coggins, R., Howard, S., Kiran, K., Harter, P., Sowb, Y., Gaba, D. and Krummel, T. (2003) 'Emergency medicine crisis resource management (EMCRM): pilot study of a simulation-based crisis management course for emergency medicine', Academic Emergency Medicine, Vol. 10, No. 4, pp.386-389.

Rosen, M.A., Salas, E., Silvestri, S., Wu, T.S. and Lazzara, E.H. (2008) 'A measurement tool for simulation-based training in emergency medicine: the simulation module for assessment of resident targeted event responses (SMARTER) approach', Simulation in Healthcare, Vol. 3 , pp.170-179.

Rousseau, D.M. (1985) 'Issues of level in organizational research: multi-level and cross-level perspectives', Research in Organizational Behavior, Vol. 7, No. 1, pp.1-37.

Rousseau, V., Aubé, C. and Savoie, A. (2006) 'Teamwork behaviors a review and an integration of frameworks', Small Group Research, Vol. 37, No. 5, pp.540-570.

Salas, E., Rosen, M.A., Burke, C.S., Nicholson, D. and Howse, W.R. (2007) 'Markers for enhancing team cognition in complex environments: the power of team performance diagnosis', Aviation, Space, and Environmental Medicine, Vol. 78, No. 1, pp.77-85.

Schaafstal, A.M., Johnston, J.H. and Oser, R.L. (2001) 'Training teams for emergency management', Computers in Human Behavior, Vol. 17, No. 5, pp.615-626. 
Sexton, J.B. and Helmreich, R.L. (2000) 'Analyzing cockpit communications: the links between language, performance, error, and workload', Journal of Human Performance in Extreme Environments, Vol. 5, No. 1, p.6.

Sexton, J.B. and Helmreich, R.L. (2003) 'Using language in the cockpit: relationships with workload and performance', Communication in High Risk Environments, Vol. 12, No. 1, pp.57-74.

Shanahan, C., Best, C., Finch, M. and Sutton, C. (2007) Measurement of the Behavioural, Cognitive, and Motivational Factors Underlying Team Performance, Air Operations Division, Defence Science and Technology Organisation, Australian Government, Department of Defence.

Shapiro, M.J., Gardner, R., Godwin, S.A., Jay, G.D., Lindquist, D.G., Salisbury, M.L. and Salas, E. (2008) 'Defining team performance for simulation-based training: methodology, metrics, and opportunities for emergency medicine', Academic Emergency Medicine, Vol. 15, No. 11, pp.1088-1097.

Small, S.D., Wuerz, R.C., Simon, R., Shapiro, N., Conn, A. and Setnik, G. (1999) 'Demonstration of high-fidelity simulation team training for emergency medicine', Academic Emergency Medicine, Vol. 6, No. 4, pp.312-323.

Smith, E., Borgvall, J. and Lif, P. (2007) Team and Collective Performance Measurement, DSTL, Policy and Capability Studies, Bedford Technology ParkThurleigh, Bedfordshire, UK.

South Australian Country Fire Service (2011) Chief Officer's Standing Orders: Standard Operating Procedures and Operations Management Guidelines, South Australian Country Fire Service, Adelaide.

Thomas, E., Sexton, J. and Helmreich, R. (2004) 'Translating teamwork behaviours from aviation to healthcare: development of behavioural markers for neonatal resuscitation', Quality \& Safety in Health Care, Vol. 13, Suppl. 1, pp.i57-i64.

Thompson, K. (2013) 'Qualitative research rules: using qualitative and ethnographic methods to acknowledge the human dimensions of technology', in Naweed, A., Bearman, C., Dorrian, J., Rose, J., Dawson, P.D., Dorn, L., Glendon, A.P.I. and Matthews, P.G. (Eds.): Evaluation of Rail Technology: A Practical Human Factors Guide, Ashgate Publishing Limited, Burlington, Vt.

Tims, M., Bakker, A.B., Derks, D. and van Rhenen, W. (2013) 'Job crafting at the team and individual level: Implications for work engagement and performance', Group \& Organization Management, Vol. 38, No. 4, pp.427-454.

Undre, S., Healey, A., Darzi, A. and Vincent, C. (2007) 'Observational teamwork assessment for surgery (OTAS): refinement and application in urological surgery', World Journal of Surgery, Vol. 31, No. 7, pp.1373-1381.

Van Der Haar, S., Segers, M. and Jehn, K. (2013) 'Measuring the effectiveness of emergency management teams: scale development and validation', International Journal of Emergency Management, Vol. 9, No. 3, pp.258-275.

Walker, S., Brett, S., McKay, A., Lambden, S., Vincent, C. and Sevdalis, N. (2011) 'Observational skill-based clinical assessment tool for resuscitation (OSCAR): development and validation', Resuscitation, Vol. 82, No. 7, pp.835-844.

Wallin, C.J., Meurling, L., Hedman, L., Hedegård, J. and Felländer-Tsai, L. (2007) 'Target-focused medical emergency team training using a human patient simulator: effects on behaviour and attitude', Medical Education, Vol. 41, No. 2, pp.173-180.

Weick, K.E. (1993) 'The collapse of sensemaking in organizations: the Mann Gulch disaster', Administrative Science Quarterly, Vol. 38, No. 4, pp.628-652.

Wilson, K.A., Salas, E., Priest, H.A. and Andrews, D. (2007) 'Errors in the heat of battle: taking a closer look at shared cognition breakdowns through teamwork', Human Factors: The Journal of the Human Factors and Ergonomics Society, Vol. 49, No. 2, pp.243-256. 
Yule, S., Flin, R., Maran, N., Rowley, D., Youngson, G. and Paterson-Brown, S. (2008) 'Surgeons' non-technical skills in the operating room: reliability testing of the NOTSS behavior rating system', World Journal of Surgery, Vol. 32, No. 4, pp.548-556.

Yule, S., Flin, R., Paterson-Brown, S., Maran, N. and Rowley, D. (2006) 'Development of a rating system for surgeons' non-technical skills', Medical Education, Vol. 40, No. 11, pp.1098-1104.

Zaccaro, S.J., Banks, D., Kiechel-Koles, L., Kemp, C. and Bader, P. (2009) Leader and Team Adaptation: The Influence and Development of Key Attributes and Processes, US Army Research Institute for the Behavioral and Social Sciences, Crystal City, VA, USA.

\section{Note}

${ }^{1}$ For a review of some of these measurement techniques see Shanahan et al. (2007). 